\title{
Client Satisfaction in Thalassemia Control Unit, North Bengal Medical College and Hospital, Darjeeling District, West Bengal
}

\author{
Nilanjana Ghosh ${ }^{1}$ and Indranil Chakrabarti ${ }^{2 *}$ \\ 'Department of Community Medicine, North Bengal Medical College, West Bengal, India \\ ${ }^{2}$ Department of Pathology North Bengal Medical College, West Bengal, India
}

\begin{abstract}
Background: Health of a nation lies in hands of its people. India harbours a huge load of thalassemia , the fatal yet preventable condition, in various forms. Haemoglobin E has prevalence of 3-10\% in West Bengal and is believed to be harboured mostly by Rajbanshis, who form majority of the local population in this terrain. Hence effective utilization of services provided is of utmost importance. Satisfaction of clients determines optimum service utilization, an indicator of effective health outcome and desirable health indicators. Accountability, accessibility, availability and sensitivity to felt needs of community by health staffs engaged in service delivery ensure satisfaction among beneficiaries. Thalassemia control unit (TCU) is a state government endeavour which aids in case and carrier detection through screening programs and there further management. The objectives of the study were to assess client satisfaction among beneficiaries regarding various aspects of services provided to them at TCU and resolve issues with managerial skills.
\end{abstract}

Methods: Study was conducted in TCU of North Bengal Medical College for six months. Study subjects were selected by systematic random sampling technique pertaining to study criteria. 120 beneficiaries were studied. Predesigned, pretested schedule adapted from CSQ8 Questionnaire was applied and exit interview was done. Satisfaction of clients in different components was assessed and means scores compared. Health staffs were also interviewed.

Results: Among selected beneficiaries 40 were known to health staffs at clinic. Majority were adults, Hindus, females and illiterates. Satisfaction level regarding different components varied among respondents. Significant difference was noted among two groups of respondents regarding behaviour of staffs at the clinic. Managerial issues were addressed after prioritization and categorization.

Conclusion: Satisfaction levels varied for different components among respondents. Significant difference was noted regarding behaviour of staff to known beneficiaries .Various issues existed which were neglected but could be addressed with managerial skills. Appropriate health education and sensitive interventions may prove beneficial. However, a larger study with more representative sample is warranted.

Keywords: Thalassemia, Client Satisfaction, Management

\section{Introduction}

Client centred, need based, demand driven services are strongly interwoven between service providers and beneficiaries. They need to work in unison and develop mutual trust and accountability to ensure appropriate service delivery, adequate service utilization, effective health outcomes and desirable health indicators ${ }^{1}$.

Thalassemias the dreaded yet preventable disease with fatal complications are the most common inherited hemoglobinopathies in India and pose a huge economic burden to the country. Hemoglobinopathies, namely hemoglobin $(\mathrm{Hb})$ variants, thalassemia syndromes, hereditary persistence of foetal haemoglobin (HPHF) and their combinations show a wide variation of prevalence in different regions and different populations. Around 1.5\% of the world's population carries the beta thalassemia gene. Hemoglobin E has a prevalence of 3-10\% in West Bengal and is believed to be harbored mostly by Rajbanshis, who form the majority of the local population ${ }^{2}$.
TCU (Thalassemia control unit) has been set up in various tertiary care hospitals by GoI and state government's initiative to aid in carrier and case detection through screening, awareness generation and counselling sessions. They provide curative, promotive ,preventive and rehabilitative care in form of premarital counselling, screening programs and arranging for chelation therapies ${ }^{3}$. This endeavour not only helps treat the cases and decrease the disease burden but also provide a host of services including field activities and monitoring and supervising other small hospitals engaged in similar service.

Clients in health sector are either patients who come solely for curative purpose or beneficiaries who avail preventive and promotive and curative services. It is well known that for effective health outcome and desirable health indicators optimum service utilization by the beneficiaries is an essential prerequisite. Hence ensuring their satisfaction for whom the services are designated and designed is of paramount importance. Standards being main drivers of 
quality, client satisfaction among beneficiaries regarding various aspects of services provided are of utmost concern and a burning issue ${ }^{4}$.

Health staffs engaged in the service delivery and the beneficiaries utilizing them are very vulnerable unless driven, owned and firmly embedded by each other. Appropriate utilization of these essential client centred, need based, demand driven services largely depends on awareness, involvement, motivation and attitude of beneficiaries towards them. Moreover, illiteracy, ignorance, lack of awareness, age old customs, fixed firm false beliefs, deep rooted faith in traditional healers and lack of credibility of public health facilities and other related areas of their dissatisfaction are some other burning issues which need to be addressed ${ }^{5}$.

Better health care decisions can be made by the beneficiaries only if they find the designated health care service planned for them accessible, affordable and available. Rural and hilly terrains are perceived to be neglected. Moreover dearth of literature on the issue in the area pertains. Thus in the aforesaid context the present study was conducted with the following objectives.

To determine satisfaction among beneficiaries regarding various aspects of services provided to them.

Categorization and prioritization of the relevant issues according to their varying degree of severity and addressing them by appropriate strategy designing and planned interventions.

\section{Materials and Methods}

Descriptive, cross-sectional, hospital based study for six months (April -August 2016) was conducted in TCU, $\mathrm{NBMCH}$, a 500 bedded hospital situated in foot-hills of Darjeeling district. All beneficiaries attending the clinic on outdoor days comprised the sampling frame. Taking prevalence as $50 \%, 10 \%$ as allowable error and $20 \%$ non responders, final sample size was calculated to be 120 . Applying systematic random sampling technique, the required study subjects were selected after calculating sampling interval.

Inclusion criteria included those having outdoor ticket of the hospital and respondents not willing to participate in the study, seriously ill and having documented mental illness were excluded. It was noted that 40 beneficiaries $(33.33 \%)$ were known to the service providers and 80 $(66.66 \%)$ were unknown to them. Health staffs engaged in service delivery were also interviewed.

Predesigned, pretested semi-structured schedule for beneficiaries and health staffs, relevant record review, tape recorder, IEC materials were tools used and study techniques applied were exit - interview method for beneficiaries, in-depth interview with health staffs engaged in delivering the services, relevant record review, focused -group-discussions (FGDs) to elicit and address issues and demonstration of IEC materials.

Data Collection and Analysis: Ethical clearance was obtained from the institutional ethics committee, NBMCH and permission from requisite higher authorities and the concerned were duly obtained. Purpose and benefits of the study was explained to health staff and respondents. Anonymity and confidentiality of the study was ensured. Informed verbal voluntary consent from the respondents and other health staffs engaged in service delivery was obtained.

Data was collected using appropriate tools and techniques. Questionnaires were administered not disrupting their routine work. FGDs conducted after their routine work also highlighted certain issues which were addressed simultaneously.

Data was cleaned, collated cross-checked, compiled and entered in Microsoft Excel. Principles of descriptive and inferential statistics were applied for data analysis. Appropriate statistical software was used. Data was represented in forms of tables and charts in the result section.

Assessment of Satisfaction: Satisfaction of the clients regarding various aspects of services provided to them at sub-centre level was assessed as follows:

Satisfaction was assessed using a modified questionnaire adapted from Client Satisfaction Questionnaire 8(CSQ8), which is commonly used to assess satisfaction of clients in health sector in and outside the country ${ }^{3}$. The questionnaire after modification was translated, back translated then validated and pretested before final application. The questionnaire had 8 components each with one single item. The components were range of services provided, quality of services provided, crisis management services available, duration of waiting time spent before availing the service, availability of health staff at the clinic, behaviour of health staff, perceived involvement of the health staff in fields and recommending others. Each reported a single score measuring a single dimension of overall satisfaction. Thus for each component minimum response was 1 and maximum response 5. Each respondent gave a score/ response for the single item in each component. Satisfaction for each component was assessed using a 5 point Likert's scales where 1 - very dissatisfied,2- dissatisfied, 3- neither satisfied nor dissatisfied, 4- satisfied, 5- very satisfied ${ }^{4}$. 
Accordingly the level of satisfaction was categorized and compared. Collected data was analyzed and presented using the principles of descriptive statistics and student's $t$ test was applied to compare the mean score of satisfaction between the two groups, respondents known to the health staffs working at the clinic and those not known to them, who had come on their own.

\section{Result}

120 beneficiaries were studied. It was noted that among them 40 respondents were known to the health staffs working at the TCU. There were no non-responder.

Basic Descriptors: Majority of beneficiaries were Hindus. $72.5 \%$ and $46.7 \%$ of beneficiaries were females and belonged to general caste respectively. $28.4 \%$ were illiterates though most of the beneficiaries resided in urban areas. Among respondents, $53.4 \%$ were adults and for the $17.2 \%$ minors, their respective caregiver opined on their behalf. (Table1, Fig.1)

80 beneficiaries $(66.6 \%)$ were not known to the staff and had come on their own for availing the service. Respondents opined that they frequently visited the tertiary care hospital for availing various services. It was found that as high as $50 \%$ were aware about the purpose of functioning of TCU.

Other findings: Client satisfaction among the beneficiaries was assessed on a 5 point Likert's scale ${ }^{5}$. Levels of satisfaction of respondents were assessed for each of the 8 components individually, in relation to the various aspects of services provided to them.

$53.4 \%, 47.5 \%, 49.2 \%$ and $53.4 \%$ of total respondents were satisfied with range of services / facilities provided to them, waiting time spent before availing the service, availability of the health staffs at the clinic and behaviour of health staffs at the clinic respectively. $50.8 \%$ were neither dissatisfied nor satisfied with quality and extent of regular services provided. Interestingly regarding the crisis management services available like arranging for blood transfusion, or reaching out a patient in times of acute need, respondents who came on their own were dissatisfied but those who knew the health staffs were neither satisfied nor dissatisfied with the service. However regarding recommending others to the clinic and regarding the involvement of the health staffs with the community during field visits, majority of respondents were neither satisfied nor dissatisfied.

The mean score of satisfaction in 7 components among the two groups of respondents, those known and those not known to the health staffs of the TCU were found to be not significantly different. However regarding behaviour and humaneness of the health staffs, the mean score of satisfaction was observed to be significantly different among the two groups. (Table 3)

In depth interview with health staffs engaged in the clinic was conducted for ascertaining the various aspects of services provided and identifying the bottlenecks faced by them, if any.

It was noted that though majority of respondents who were unknown to health staffs were dissatisfied with crisis management services. Most of the respondents were neither satisfied nor dissatisfied with quality of services available. However, they said they would recommend others as they had no other option.

The health staffs engaged cited logistic constraints, poor amount of technical knowhow and improper functioning of the machines as their limitations. They also opined that beneficiaries unknown to them had no accountability and viewed them with suspicion and wanted more centres to be run, more deployment of other staffs during field visits, starting of chelation therapy so that accountability could generate among respondents. A designated senior staff who could monitor and provide supportive supervision would help further. Moreover duty performance would improve if appropriate infrastructural support and division of labour is ensured.

However few issues could be resolved locally with apt managerial skills, proper technical knowhow, careful understanding of the topic and culture sensitive interventions. The problems were prioritized and categorized into four sections according to their varying degrees of severity. Thus remedies applying appropriate managerial skill and technical knowhow were attempted.

(Table 4)

It was noted with intense awareness generation the attendance of the patients visiting the outdoor of the thalassemia clinic had increased. Respondents asked for pamphlets for their neighbours. Many adolescents and teenagers turned up and asked for relevant literature on the topic which was an important finding indicating the positive effect of awareness generation.

\section{Discussion}

Community based studies are representative of actual situation prevailing in the area, as the tests and interviews are carried out in their natural settings. Rajbanshis emerged as of the most predominant ethnic group in this area. They are survivors of an aboriginal race. ${ }^{7}$ Significant association between Rajbanshis, living in the northern 
Table 1a: Distribution of Study Subjects According to Age

\begin{tabular}{|l|c|c|}
\multirow{2}{*}{ Age $(\mathbf{y r s})$} & \multicolumn{2}{|c}{ Total $(\mathbf{n = 1 2 0})$} \\
\cline { 2 - 3 } & No. & \multicolumn{2}{|c}{ Percentage } \\
\hline Adults $(>18$ yrs) & 64 & 29.4 \\
\hline 15 yrs. -18 yrs. & 35 & 17.5 \\
\hline Minors (<15 yrs) & 21 & 100 \\
\hline Total & $\mathbf{1 2 0}$ & 100 \\
\hline
\end{tabular}

Table 1b: Distribution of respondents according to highest literacy status

\begin{tabular}{|l|c|c|}
\multirow{2}{*}{ Highest literacy status } & \multicolumn{2}{|c}{ Total Respondents ( $\mathbf{n = 1 2 0})$} \\
\cline { 2 - 3 } & No. & 28.4 \\
\hline Illiterate & 34 & 24.2 \\
\hline Just literate & 29 & 20.8 \\
\hline Passed primary school & 25 & 11.7 \\
\hline Completed X & 14 & 10.0 \\
\hline Completed XII & 12 & 05.0 \\
\hline Graduate/above & 6 & $\mathbf{1 0 0}$ \\
\hline Total & $\mathbf{1 2 0}$ & \\
\hline
\end{tabular}

Table 2: Assessing satisfaction among respondents

Table 2 a: Distribution according to satisfaction levels regarding range of services provided

\begin{tabular}{|c|c|c|c|c|c|c|}
\hline \multirow{2}{*}{$\begin{array}{l}\text { Levels of } \\
\text { satisfaction }\end{array}$} & \multicolumn{2}{|c|}{$A(n=80)$} & \multicolumn{2}{|c|}{$B(n=40)$} & \multicolumn{2}{|c|}{ Total $(n=120)$} \\
\hline & No. & Percentage & No. & Percentage & No. & Percentage \\
\hline 1 & 2 & 2.5 & 2 & 5 & 4 & 3.3 \\
\hline 2 & 11 & 13.7 & 6 & 15 & 17 & 14.2 \\
\hline 3 & 21 & 26.2 & 9 & 22.5 & 30 & 25 \\
\hline 4 & 43 & 53.7 & 21 & 52.5 & 64 & 53.4 \\
\hline 5 & 3 & 3.7 & 2 & 5 & 5 & 4.1 \\
\hline
\end{tabular}

Table 2 b: Distribution according to satisfaction levels regarding waiting time spent

\begin{tabular}{|c|c|c|c|c|c|c|}
\multirow{2}{*}{ Satisfaction levels } & \multicolumn{2}{|c|}{$\mathbf{A}(\mathbf{n = 8 0})$} & \multicolumn{2}{c|}{ Total $(\mathbf{n = 1 2 0 )}$} \\
\cline { 2 - 7 } & No. & Percentage & No. & Percentage & No. & Percentage \\
\hline 1 & 4 & 5 & 2 & 5 & 6 & 16 \\
\hline 2 & 13 & 16.2 & 3 & 7.5 & 27 & 22.5 \\
\hline 3 & 16 & 20 & 11 & 27.5 & 57 & 47.5 \\
\hline 4 & 38 & 47.5 & 19 & 47.5 & 14 & 11.7 \\
\hline 5 & 9 & 11.2 & 5 & 12.5 & & 5 \\
\hline
\end{tabular}

Table 2 c: Satisfaction levels regarding availability of health staffs at clinic

\begin{tabular}{|l|c|c|c|c|c|c|}
\multirow{2}{*}{ Satisfaction levels } & \multicolumn{2}{|c|}{ A (n=8) } & \multicolumn{2}{c|}{ B (n=40) } & \multicolumn{2}{c|}{ Total (n= 120) } \\
\cline { 2 - 8 } & No. & Percentage & No. & Percentage & No. & Percentage \\
\hline 1 & 4 & 5 & 1 & 2.5 & 10 & 22 \\
\hline 2 & 18 & 22.5 & 4 & 12.5 & 27 & 22.5 \\
\hline 3 & 22 & 27.5 & 5 & 65 & 59 & 49.2 \\
\hline 5 & 33 & 41.2 & 26 & 10 & 7 & 5.8 \\
\hline
\end{tabular}


Table 2d: Satisfaction level regarding behaviour and humaneness of health staffs

\begin{tabular}{|c|c|c|c|c|c|c|}
\hline \multirow{2}{*}{ Satisfaction levels } & \multicolumn{2}{|c|}{$A(n=80)$} & \multicolumn{2}{|c|}{$B(n=40)$} & \multicolumn{2}{|c|}{ Total $(n=120)$} \\
\hline & No. & Percentage & No. & Percentage & No. & Percentage \\
\hline 1 & 2 & 2 & 2 & 5 & 4 & 3.3 \\
\hline 2 & 12 & 15 & 4 & 10 & 16 & 13.3 \\
\hline 3 & 22 & 27.5 & 9 & 22.5 & 31 & 25.8 \\
\hline 4 & 41 & 51.2 & 23 & 57.5 & 64 & 53.4 \\
\hline 5 & 3 & 3.7 & 2 & 5 & 5 & 4.2 \\
\hline
\end{tabular}

Table 2e: Satisfaction level according to the crisis management services available

\begin{tabular}{|c|c|c|c|c|c|c|}
\hline \multirow{2}{*}{ Satisfaction level } & \multicolumn{2}{|c|}{$A(n=80)$} & \multicolumn{2}{|c|}{$B(n=40)$} & \multicolumn{2}{|c|}{ Total $(n=120)$} \\
\hline & No. & Percentage & No. & Percentage & No. & Percentage \\
\hline 1 & 6 & 7.5 & 4 & 10 & 10 & 8.4 \\
\hline 2 & 31 & 38.7 & 14 & 35 & 45 & 37.5 \\
\hline 3 & 29 & 36 & 16 & 40 & 45 & 37.5 \\
\hline 4 & 11 & 13.7 & 4 & 10 & 15 & 12.5 \\
\hline 5 & 3 & 3.7 & 2 & 5 & 5 & 4.2 \\
\hline
\end{tabular}

Table $2 \mathrm{f}$ : Satisfaction levels regarding quality and extent of regular services provided

\begin{tabular}{|c|c|c|c|c|c|c|}
\hline \multirow{2}{*}{ Satisfaction levels } & \multicolumn{2}{|c|}{$A(n=80)$} & \multicolumn{2}{|c|}{$B(n=40)$} & \multicolumn{2}{|c|}{ Total $(n=120)$} \\
\hline & No. & Percentage & No. & Percentage & No. & Percentage \\
\hline 1 & 3 & 3.7 & 3 & 7.5 & 6 & 5 \\
\hline 2 & 22 & 27.5 & 10 & 25 & 32 & 26.7 \\
\hline 3 & 41 & 51.2 & 20 & 50 & 61 & 50.8 \\
\hline 4 & 12 & 15 & 5 & 12.5 & 17 & 14.2 \\
\hline 5 & 2 & 2 & 2 & 5 & 4 & 3.3 \\
\hline
\end{tabular}

Table 2 g: Satisfaction levels regarding involvement of health staffs in field

\begin{tabular}{|c|c|c|c|c|c|c|}
\hline \multirow{2}{*}{ Satisfaction levels } & \multicolumn{2}{|c|}{$A(n=80)$} & \multicolumn{2}{|c|}{$B(n=40)$} & \multicolumn{2}{|c|}{ Total $(n=120)$} \\
\hline & No. & Percentage & No. & Percentage & No. & Percentage \\
\hline 1 & 3 & 3.7 & 4 & 10 & 7 & 5.8 \\
\hline 2 & 22 & 27.5 & 12 & 30 & 34 & 28.4 \\
\hline 3 & 31 & 38.7 & 12 & 30 & 43 & 35.8 \\
\hline 4 & 20 & 25 & 9 & 22.5 & 29 & 24.2 \\
\hline 5 & 4 & 5 & 3 & 7.5 & 7 & 5.8 \\
\hline
\end{tabular}

Table $2 \mathrm{~h}$ : Satisfaction level regarding recommending others to the clinic

\begin{tabular}{|c|c|c|c|c|c|c|}
\hline \multirow{2}{*}{ Satisfaction levels } & \multicolumn{2}{|c|}{$A(n=80)$} & \multicolumn{2}{|c|}{$B(n=40)$} & \multicolumn{2}{|c|}{ Total $(n=120)$} \\
\hline & No. & Percentage & No. & Percentage & No. & Percentage \\
\hline 1 & 3 & 3.7 & 3 & 7.5 & 6 & 5 \\
\hline 2 & 22 & 27.5 & 10 & 25 & 32 & 26.7 \\
\hline 3 & 41 & 51.2 & 20 & 50 & 61 & 50.8 \\
\hline 4 & 12 & 15 & 5 & 12.5 & 17 & 14.2 \\
\hline 5 & 2 & 2 & 2 & 5 & 4 & 3.3 \\
\hline
\end{tabular}


Table 3: Mean satisfaction score in relation to several components of satisfaction

\begin{tabular}{|c|c|c|c|}
\hline Components of Satisfaction & Mean score $A(n=80)$ & Meanscore $B(n=40)$ & Statistical tests \\
\hline Range of services & $3.43 \pm 0.87$ & $3.38 \pm 0.98$ & $t=0.28, p=0.77$ \\
\hline Quality of services & $2.84 \pm 0.80$ & $2.83 \pm 0.93$ & $t=0.76, p=0.93$ \\
\hline Crisis management services & $2.68 \pm 0.94$ & $2.65 . \pm 0.98$ & $t=0.13, p=0.89$ \\
\hline Waiting time & $3.44 \pm 1.05$ & $3.55 \pm 0.99$ & $t=-0.56, p=0.57$ \\
\hline Availability of health staffs at clinic & $3.39 \pm 0.88$ & $3.48 \pm 0.93$ & $t=-0.50, p=0.61$ \\
\hline Behaviour of health staff & $3.16 \pm 0.99$ & $3.39 \pm 0.88$ & $t=-2.91, p=0.00$ \\
\hline $\begin{array}{l}\text { Perceived involvement of health staff } \\
\text { in fields }\end{array}$ & $3.00 \pm 0.94$ & $2.88 \pm 1.11$ & $t=0.64, p=0.52$ \\
\hline Recommending others to the clinic & $3.29 \pm 0.87$ & $3.43 \pm 0.87$ & $t=0.32, p=0.71$ \\
\hline
\end{tabular}

The values depict Mean \pm Standard Deviation

Table 4: Table categorizing and prioritizing the various relevant issues noted

\begin{tabular}{|c|c|c|c|}
\hline A & B & C & D \\
\hline Low impact on performance & $\begin{array}{l}\text { Medium to high impact - low } \\
\text { severity }\end{array}$ & $\begin{array}{l}\text { Requiring attention but } \\
\text { easy to resolve }\end{array}$ & Problems difficult to resolve \\
\hline $\begin{array}{c}\text { Delay in arriving the centre, } \\
\text { so missed that day }\end{array}$ & $\begin{array}{l}\text { Not utilizing the service due to } \\
\text { cultural festivals }\end{array}$ & $\begin{array}{l}\text { Logistic constraints - cited } \\
\text { by health staff }\end{array}$ & $\begin{array}{l}\text { Ignorance of respondents } \\
\text { regarding the purpose of clinic }\end{array}$ \\
\hline $\begin{array}{l}\text { Personal vengeance with } \\
\text { health staffs }\end{array}$ & $\begin{array}{l}\text { More field involvement of health } \\
\text { staff desired }\end{array}$ & $\begin{array}{c}\text { Improper inventory control } \\
\text { mechanism, condemnation } \\
\text { procedures }\end{array}$ & $\begin{array}{l}\text { Cultural perceptions of } \\
\text { respondents False beliefs } \\
\text { taboos of respondents }\end{array}$ \\
\hline Came on a holiday & Health staff on leave & Illiteracy of caregiver & No chelation therapy available \\
\hline $\begin{array}{l}\text { Came for re-screening even } \\
\text { if know not a carrier }\end{array}$ & $\begin{array}{l}\text { Delay in counselling } \mathrm{d} / \mathrm{t} \text { mild } \\
\text { physical illness. }\end{array}$ & $\begin{array}{l}\text { Failure of co-ordination in } \\
\text { the clinic }\end{array}$ & $\begin{array}{l}\text { Fear of loss of daily wage of } \\
\text { respondent }\end{array}$ \\
\hline - & Forgot clinic location & $\begin{array}{l}\text { Absence of monitoring and } \\
\text { supportive supervision. }\end{array}$ & $\begin{array}{l}\text { Lack of specific advice } \\
\text { provided by the health care } \\
\text { facility }\end{array}$ \\
\hline- & - & $\begin{array}{l}\text { Dissatisfaction of } \\
\text { respondents - } \\
\text { Behaviour of health staff }\end{array}$ & $\begin{array}{l}\text { Dissatisfaction of respondents } \\
\text { regarding crisis management } \\
\text { services }\end{array}$ \\
\hline May be ignored & Low priority problem & Take action to resolve & $\begin{array}{l}\text { Prepare alternative solution to } \\
\text { resolve }\end{array}$ \\
\hline
\end{tabular}

part of W.Bengal and $\mathrm{HbE}$ hemoglobinopathies exists. Prevalence of $\mathrm{HbE}$ trait was found to be highest amongst all hemoglobinopathies. Increased occurrence of $\mathrm{HbE}$ in this area is similar to found in Assam and Tripura hinting at lineage simulation between the Rajbanshis and these states. Hill tribes, mainly adivasis, also showed a high $\mathrm{HbE}$ occurrence, thus indicating intra racial marriages with Rajbanshis and acculturation. Adivasis, who emigrated into Northern part of West Bengal for tea cultivation from Chotanagpur plateau, their results also match with the residents of central east coast of India.,

A detailed comparative insight becomes imperative to understand the dynamics of adequate service utilization for assuring effective health outcomes. The study was a hospital based descriptive, cross-sectional study with a small sample size and may not be comparable to other studies in true sense but an attempt to interpret findings of present study in light of other studies will help create an overall view and a holistic approach.
Majority of the respondents were illiterates. Similar to present a study conducted on utilization and coverage quality of antenatal care services in Bankura,W.Bengal found $52.4 \%$ respondents to be illiterates. ${ }^{6}$ Illiteracy poses a major hindrance for utilization of services.

Client satisfaction is a burning issue and warrants immediate attention and interventions. Satisfaction of beneficiaries was thus assessed and compared with other studies. Various studies have been conducted on client satisfaction in health care settings, both inside and outside India.

In a study on community health workers, Berman concluded that involvement in field activities embed the health workers are part of community and make them more acceptable enhancing overall service coverage. Study also noted that accessibility of workers combined with equity in services increases the trust and morale of the beneficiaries, especially those who are not known to the 
health staffs. Vaccination camps were evaluated in urban areas of Mexico and in communities dispersed along a river in Amazon, Ecuador. It was seen that round the clock availability and good behaviour of the health staffs resulted in improved coverage. ${ }^{7}$

In another study it was seen that $95 \%$ respondents opined that health workers had friendly attitude and provided a range of good quality services. However inconvenient timings and long waiting time was a major obstacle in their service utilization. A study carried out in Delhi found that average total satisfaction score was $84.79 \%$ of maximum possible scores. It was found that human factors were more related with concepts of satisfaction than the physical factors ${ }^{8}$.

A study by U. Kapil on utilization of health care facilities by at risk children, found that in $37 \%$ cases prolonged waiting time, in $12.03 \%$ cases unpleasant behaviour of hospital staff, in $16 \%$ cases non availability of drugs, in $35 \%$ cases inconvenience of timings and in $14 \%$ cases unsatisfactory treatment were reasons for not availing health services. ${ }^{8}$

\section{Conclusion:}

Present study concludes that satisfaction levels among the respondents vary. Alarmingly, significant difference exists between respondents known and unknown to health staff regarding their behaviour .

Many local issues persist in the health care setting which can be resolved by monitoring, understanding and applying managerial skills. However some issues warrant larger and higher level intervention. On categorizing the problems according to their severity and priority various issues could be identified promptly. Timely interventions, supportive supervision go a long way in successful implementation of any program.

\section{Recommendations}

It is unfortunate for a tertiary care hospital with specialist services to suffer from lack of convergence of service. Appropriate referrals to TCU and opening of chelation therapies are need of the hour. Intensive awareness generation and appropriate health education imparted on relevant and related issues pave way for better service utilization. Efforts to improve community participation should be attempted with vigour and convergence of various health services and alerting physicians in the entire hospital for conveying the appropriate advice and referring the needy to TCU is required.

However it is imperative that a larger community based study with liberal fund allocation and other logistic support is strongly recommended.

\section{Acknowledgements}

We are grateful to the staff of Thalassemia Control Unit for their support

\section{Reference}

1. Goswami BK, Pramanik R, Chakraborty S, Pal PP, Banerjee S, Bandopadhyay A.Spectrum of Hemoglobin Variants in the Population of Northern Region of West Bengal: An Ethnogenetic Proposition, J Family Med Prim Care. 2014 Jul-Sep; 3(3): 219-223

2. Verma IC, Saxena R, Thomas E, Jain PK. Regional distribution of $\beta$-thalassemia mutations in India. Hum Genet. 1997;100:109-113.

3. Larsen DL, Attkisson CC, Hargreaves WA, Nguyen TD. Assessment of client/patient satisfaction: Development of a general scale, Evaluation and Program Planning. 1979; 197-207. Available from http://www.CSQscales.com /.[last accessed on 2016 July 26]

4. Tabish S A. Health Planning. In: Tabish SA,editor. Hospital and Health Services administration: Principles and Practice,3rd ed. New Delhi: Oxford University Press; 2005. p. 43-51.

5. Discussion Paper on Scales for Measuring Customer Satisfaction. Available from: www.marketdirectionsmr. com/wp-files/wp.../02/SurveyScales.pdf [last accessed on 2016 June 7]

6. Sinhababu A, Mahapatra BS, Das D, Mundle M, Soren AB, Panja TK. A study on utilization and quality of coverage of antenatal care services at the subcentre level. Indian J Public Health. 2006;50(1):49-52.

7. Aikat A, Biswas R. In search of a new accountability: the voice of patients. The Health 2011; 2(2):48-50.

8. Kapil U. Utilisation of health care facilities by "At risk" children. Indian J Community Med 1989; 14(2):83-4.

*Corresponding author:

Dr Indranil Chakrabarti, Associate Professor, Department of Pathology, North Bengal Medical College, West Bengal, India

Phone: +919433187448

Email: drinch@rediffmail.com

Date of Submission : 04.02.2017

Date of Acceptance : 17.02.2017

Financial or other Competing Interests: None.

Date of Publication : 21.02.2017 